\title{
Els orígens de l'Estudi General de Girona: uns començaments que es faran esperar
}

\section{The Origins of the Estudi General of Girona: A long Way}

\author{
XAVIER TORRES \\ xavier.torres@udg.edu \\ Universitat de Girona
}

Resum: Els orígens i la trajectòria mateixa de l'Estudi General de Girona (1446-1717) són força mal coneguts encara, sobretot per unes mancances documentals que semblen de mal solucionar a curt i potser a llarg termini. En aquestes pàgines s'ofereix, doncs, una síntesi de l'evolució del vell Estudi gironí, tot remarcant el seus inicis més aviat tardans, a la segona meitat del segle XVI, és a dir, un segle després de l'obtenció del pertinent privilegi reial. Aquesta lenta arrencada de la universitat gironina es pot explicar per les vicissituds polítiques, econòmiques i religioses tant del període com de la ciutat de Girona.

Paraules clau: Universitat, Girona, Època moderna, Estudis superiors

\begin{abstract}
The origins and the secular evolution of the Estudi General de Girona are not yet well known because of a notorious lack of sources. Such a problem does not seem to have an easy solution in the short and even long term. Therefore, only a general view can be offered at the moment. Such a survey remarks the laborious beginnings of the old Girona university, a century after the perceptive royal permission was given. Besides, the long way of the Estudi is related to the political, economic and religious events of the period, as well as the city.
\end{abstract}

Key words: University, Girona, Early Modern History, University studies

\footnotetext{
* Una versió anterior d'aquest treball es pot trobar a Torres (2011). Ara s'hi actualitzen algunes dades, s'amplia la bibliografia, es reajusta el sistema de citació de fonts i se’n canvia la introducció.
} 
Potser cal fer-ho avinent de bon començament: els orígens i l'evolució mateixa de l'Estudi General de Girona (1446-1717) són força mal coneguts encara. Sobretot, és clar, per uns dèficits documentals que semblen de mal solucionar a curt i potser a llarg termini; i que contrasten, dit sigui de passada, amb la riquesa de restes o fonts d'una altra mena. En unes altres paraules, la història arquitectònica i fins i tot artística de la vella universitat gironina és a hores d'ara més ben coneguda que no pas la seva trajectòria institucional i intel lectual (AA. DD. 2011: 165-244). Les pedres, doncs, no sols han resistit millor el pas del temps (la qual cosa era potser previsible), sinó també els successius setges de la ciutat (de la Guerra dels Segadors a la Guerra del Francès), mentre que els papers, escadussers, no tenen una fàcil substitució. En aquestes pàgines, doncs, no podem sinó assajar una síntesi de l'evolució del vell Estudi gironí, i suggerir, de passada, algunes hipòtesis, tal vegada excessives o precipitades. En qualsevol cas, una veritable història de l'Estudi General gironí no pot deixar de costat la ciutat. Ni l'Església. Però mentre la capitalitat diocesana i tot allò que comporta es poden considerar un factor relativament constant al llarg del període considerat, les oscil lacions de l'economia urbana, inevitables, tenen una incidència prou directa en el rumb dels estudis superiors locals. I viceversa. Perquè si unes vegades la universitat empeny la ciutat -tal com ha passat amb la Universitat de Girona d'ençà de la dècada del 1990- altres cops ha estat ben bé a l'inrevès.

\section{Un privilegi medieval (1446)}

Els orígens de l'Estudi General gironí es poden considerar una emanació, encara que sigui retardada, d'aquell moviment intel lectual i polític engegat pels volts del segle xiII a l'Occident feudal -se'n digui prerenaixement $\mathrm{o}$ com es vulgui- i que propicià l'aparició i multiplicació d'una nova mena d'establiments d'educació superior. Al Principat de Catalunya, Lleida va prendre la davantera, amb l'erecció, l'any 1300, d'un Estudi General, en règim de monopoli i amb vocació d'esdevenir la universitat de tota la Corona d'Aragó. Perpinyà (1350) i Osca (1354) li van disputar ben aviat aquesta exclusivitat. Prop d'un segle després, ho feien Girona (1446) i Barcelona (1450). Però mentre les autoritats barcelonines -almenys en temps de Martí l'Humà- mai no amagaren les seves reticències davant l'emergència d'una corporació universitària local, amb el seu seguit inevitable de llibertats i exempcions particulars, els jurats gironins, per contra, igual com els capitulars de la Seu local, sol licitaren amb vehemència, l'any 1446, al rei i al papa, la creació d'un Estudi General a la ciutat.

La Girona de mitjan segle xv era una capital comarcana de prop de 900 focs, és a dir, uns 4.500 habitants. Hi predominaven les activitats manufactureres, assenyaladament la draperia o elaboració de teixits de llana, però també hi havia un nombre insòlitament elevat de professionals de la lletra (escrivans, notaris, juristes), un fet que s'explica segurament per la simultània capitalitat diocesana de la ciutat. La població eclesiàstica era igualment significativa i rondava, sembla, les 250 persones (Sobrequés, 1975). Un Estudi General, doncs, no sols trobaria un terreny adobat, sinó que, a més, podia contribuir -escrivien els jurats gironins al rei- a l'«angmentatio d'aquesta vostra ciutat». A 
banda dels avantatges d'ordre pràctic $i$ intel lectual, darrere una iniciativa semblant hi havia també un no gens dissimulat desig d'emulació local (sobretot en relació amb Lleida) i fins i tot l'esperança de guanyar posicions dins la jerarquia urbana del conjunt del Principat: un rànquing dins el qual la Girona d'aleshores ocupava un cinquè lloc, darrere de Barcelona, és clar, però també per sota de Perpinyà, Lleida i Tortosa, que li triplicaven o duplicaven els efectius demogràfics.

La resposta del rei no es va fer esperar -a diferència de la de Roma, que no arribà fins a principis del segle XVII. Així, a primers de març de l'any 1446, Alfons el Magnànim, de Nàpols estant, signava el privilegi que autoritzava els jurats gironins a erigir un Estudi General amb totes aquelles facultats que volguessin o poguessin mantenir (s'esmentaven expressament, però, els estudis «in morali et naturali scientia et doctrina utriusque iuris»). Malgrat aquesta celeritat, els inicis de l'anhelat Estudi General gironí es retardaren més de cent anys. Igual, si fa no fa, que l'Estudi barceloní, però per motius una mica diferents, potser. La conjuntura immediata no era pas gaire propícia enlloc. La crisi baixmedieval, que s'arrossegava de feia prop d'un segle, va significar una caiguda substancial tant de l'activitat econòmica com de la població, i això tant a Girona com a la capital catalana. La Girona de la segona meitat del segle xv també patí, però, els excessos de la guerra entre Joan II i la Diputació catalana (1462-1472), amb tres setges de la Força Vella, i les seqüeles del conflicte, assenyaladament les perdurables bandositats comarcanes i les periòdiques campanyes militars per la recuperació del comtat del Rosselló (1473-1475) (Masià de Ros, 1943).

La ciutat no es va refer fins a principis del segle XVI, quan es reprengueren, amb una embranzida renovada, les activitats tèxtils tradicionals. Paral lelament, la població, ajudada per una nodrida immigració francesa, també remuntà. A mitjan segle Xvi Girona no sols superava el llindar del miler de focs (1.140) o els 5.000 habitants, sinó que també guanyava posicions en el rànquing urbà: del cinquè lloc havia passat al tercer, per darrere de Barcelona i Perpinyà, però per davant de Lleida i Tortosa (encara que fos per un centenar o dos de focs únicament). Les talles municipals -amb les seves indicacions sobre els oficis dels gironins- $\mathrm{i}$ les xifres de la bolla catalana -un impost sobre la producció i circulació de teixits de llana- testimonien l'auge de la draperia local al llarg de tota la segona meitat del segle XVI (Torres, 2001: 28-33). No és casual, doncs, que fos aleshores quan el projecte de l'Estudi General esdevingué una realitat.

La draperia i els seus guanys, però, no ho són pas tot. S'acostuma a dir que les universitats europees de l'època moderna estaven pensades per instruir tant els intel lectuals de l'Església com la burocràcia dels naixents Estats moderns. Però a l'Europa catòlica, l'impuls universitari d'aquells segles no es pot separar del clímax de la Contrareforma i el combat teològic subseqüent. No debades, a la làpida que es va posar, l'any 1561, a la façana del nou edifici de l'Estudi General, entre els escuts de la casa d'Àustria i de la ciutat de Girona, s'hi pot llegir -avui encara, i en llatí- una inscripció programàtica (que es pot traduir) d'aquest tenor: «com que l'habitant de l'Infern sembrava en diversos països les seves falses doctrines contra la santa fe, els Senadors gironins van fundar tantes aules sacres com els fou possible edificar» (AA. DD. 2011: 234). No era una invocació conjuntural, sinó un senyal 
d'identitat secular. Així, al preàmbul de les ordinacions de l'any 1685 -les més completes que tenim- les funcions de l'Estudi General es resumien en dues. D’una banda, la formació de futurs magistrats o servidors de la cosa pública, atès que, es deia, «lo més principal fonament sobre que descansa lo pes de un govern (...) sien les lletres». D'altra banda, però, hom perseguia també la «producció de subjectes» que sabessin defensar «la cathòlica y verdadera christiana fe (...) contra los vaibéns del món» (Sobrequés, 1978: 19).

\section{L'arrencada}

La primera pedra de l'edifici de l'Estudi General es va posar cap a finals de l'any 1561. A la cerimònia hi van assistir les primeres autoritats eclesiàstiques i civils, a més d'un gran nombre de ciutadans i eclesiàstics, i les principals confraries de la ciutat. Es tractava d'un establiment aixecat a la pujada dels Alemanys, damunt uns solars que el municipi va comprar a dos canonges de la catedral. Uns anys després la ciutat ampliava l'espai universitari mitjançant un seguit d'adquisicions de terrenys a la plaça de Sant Domènec, al costat del monestir homònim de predicadors. Consta que l'any 1566 ja hi havia tres aules a punt. I el 1570 s'acabava el portal de la façana de Sant Domènec. Tot i així, les obres (minuciosament estudiades per Garriga, 2011) avançaven lentament; sobretot, per falta de pressupost, i malgrat algunes generoses aportacions particulars. La construcció del nou campus universitari s'allargà fins a principis del segle XVII (1609), i les obres d'agençament de l'entorn -l'esplanada o «rambla» de Sant Domènec o de l'Estudi, tal com se'n dirà també- es prolongaren fins a començaments del segle XVIII (1701).

La contractació del professorat també va topar amb algunes dificultats. Inicialment, les autoritats gironines havien pensat encarregar l'organització docent del nou centre (professors, plans d'estudis, estatuts) a una personalitat acadèmica de prestigi i -idealment- vinculada a la ciutat. Per aquesta raó, l'estiu de l'any 1569 els jurats de Girona s'adreçaren a Antic Roca per demanar-li si volia «venir [a] residir en esta ciutat per encaminar lo Estudi que de nou edificam» o, si més no, si podia recomanarlos «algun mestre tal que pogués donar principi al dit Estudi» (Clara, 1991). La tria d'Antic Roca no era pas casual. D'origen gironí, Roca era aleshores tota una autoritat en els cercles universitaris i humanistes de Barcelona. Graduat en Arts (1555) i en Medicina (c. 1568), deixeble de Francesc Calça (1521-1603), un professor de filosofia de l'Estudi barceloní, i del lul lista Lluís-Joan Vileta (?-1583), Roca era catedràtic d'Arts a Barcelona d'ençà l'any 1559. Editor d'Àusias March (1560) i d'Antonio Nebrija (1560), Roca va ser autor també d'un tractat d'aritmètica i mercaderia (1564), i va excel lir sobretot en la confecció de manuals i comentaris aristotèlics (en la dècada de 1570). La seva vinculació amb la ciutat comtal no féu sinó augmentar en anys successius: després d'assolir el grau de cives -l'equivalent d'una petita noblesa urbana- va ser jurat del Consell de Cent (1580).

Roca va declinar l'oferiment. El primer canceller de l'Estudi General gironí va ser Bernat Cerdà (1572-1578); no sabem si per recomanació d'aquell. La figura del canceller era el vèrtex de 
l'organigrama de l'Estudi. El càrrec era de designació municipal, tenia una durada (inicial) de dos anys i havia de recaure en un canonge o una dignitat de la Seu. Per sota del canceller hi havia un rector, igualment eclesiàstic o membre de la Seu, nomenat també cada dos anys pels jurats de la ciutat, i que supervisava l'activitat tant dels professors com dels estudiants. L'equip de govern de l'Estudi es completava amb un vicerector, un cop més eclesiàstic; un secretari o administrador, i un bidell, un càrrec vitalici, nomenat pels jurats, i que, a més de tocar la campaneta per anunciar l'inici de les classes, vetllava per l'ordre a les aules. En algun moment sembla haver-hi hagut també un clavari o responsable de les finances de la institució. Els primers professors foren també nomenats pels jurats de la ciutat, tot i que a partir de l'any 1579 s'instaurà el sistema d'oposicions públiques.

Les primeres classes van començar -sembla- l'any 1572, amb dues càtedres: una de Gramàtica i un altra de Teologia. Més endavant s'hi afegiran les de Filosofia, Dret i Medicina. En el moment de màxima expansió, que sembla haver estat la segona meitat del segle xvII, l'Estudi General gironí comptava amb un total de 17 càtedres, amb la distribució següent: 7 de Teologia (Barcelona en tenia 6), 3 de Gramàtica, 3 de Filosofia o «Arts», 2 de Lleis i 2 de Medicina. Les càtedres i altres despeses anaven a càrrec, bàsicament, de la ciutat i el capítol de la Seu, tot i que algunes altres institucions, com ara la Pia Almoina, i alguns particulars també hi col laboraven esporàdicament i subsidiària. Les classes es feien entre les $7 \mathrm{i}$ les 11 hores, al matí, i de 14 a 17 hores, a les tardes. La gamma de lectures no tenia gran cosa d'original: a les classes de gramàtica, Ciceró i Nebrija; Virgili, i el De Officiis de Ciceró, quan es tractava d'història o de «reduir» els estudiants «a la vida civil y pulítica»; la Summa i la Bíblia a les classes de Teologia, i una o altra obra d'Aristòtil a les de Filosofia. Els diumenges i festius, els estudiants havien de llegir un llibre sobre les resolucions del concili de Trento (Sobrequés, 1978: 7-10; Rossich, 1982: 549-551; i amb més detall, Marquès, 2002: 131-135 i Torroella, 1906: 50-62).

No hi ha universitat sense estudiants. Però, ara com ara, sabem ben poca cosa sobre el nombre, la procedència i el perfil sociològic dels estudiants gironins del període. A començaments del segle XVII, sembla que n'arribaven regularment de Perpinyà. Però allò més habitual era que fossin de la ciutat i voltants i dels dos Empordans (Figueres, Castelló d'Empúries, La Bisbal, Corsà, Ultramort) [Girbal, 1894: 217). En qualsevol cas, les xifres d'estudiants són encara una incògnita. A la segona meitat del segle XVII -l'edat d'or de la corporació? - poden haver estat prop de 400 en total, ni que sigui (tal com sembla) acumulativament (Torroella, 1906: 61). I això, en una ciutat que aleshores no arribava als 900 focs o els 4.500 habitants; una proporció, si les dades són correctes, significativa, certament. Dels estudiants, si més no, n'han pervingut les queixes. Un ban promulgat l'any 1641, en plena Guerra dels Segadors, pels jurats gironins clamava contra «les llibertats i atreviments d'alguns estudiants», que importunaven les dones quan anaven a missa i que eren sospitosos, a més, dels robatoris que es cometien en botigues i obradors «de molts pobres menestrals» de la ciutat. El ban tampoc no estalviava un seguit de consideracions tòpiques, com ara que els mals estudiants «diverteixen los bons», els quals «aprofitarien [molt més] si no es divertissin amb llur mal exemple i companyia». També ha deixat una certa petja documental la rivalitat entre els estudiants de l'Estudi i els del col legi jesuïta de Sant Martí Sacosta, que sovint acabava amb veritables batalles campals (Sobrequés, 1978: 10-11). 


\section{Una trajectòria estroncada}

La trajectòria de l'Estudi General de Girona, igual com la de tots els de Catalunya, va estroncar-se abruptament l'any 1717, quan Felip V, vencedor de la Guerra de Successió, va decretar la clausura de tots els Estudis existents, i atorgà l'exclusivitat de l'educació superior a la tot just instaurada Universitat de Cervera. Les armes, doncs, acabaren guanyant la partida a les lletres. Girona no va ser pas una capital austriacista de primera hora, sinó més aviat una ciutat «tèbia» o expectant, igual com tantes altres del Principat. Pel que fa a l'Estudi local, l'arxiduc Carles li va concedir, l'any 1710, un efímer títol de «Reial». La institució mantenia aleshores un total de 10 càtedres: 4 de Teologia, 3 de Filosofia i 3 de Gramàtica. El 1716 a la vigília del decret d'extinció, aguantaven únicament tres càtedres de Teologia (Sobrequés, 1978: 11-12; Marquès, 2002: 144). Després, la liquidació va ser absoluta. Les rendes de l'Estudi anaren a parar, meitat per meitat, als jesuïtes de Sant Martí Sacosta i a la nova universitat borbònica de Cervera. Els estudis universitaris gironins havien trigat més d'un segle a concretar-se, i s'havien mantingut, bé o malament, durant prop d'un segle i mig. Ara, però, haurien d'esperar entre dos i tres segles per reprendre l'activitat. 


\section{Bibliografia}

AA. DD. (2011) Universitat de Girona: Història, arquitectura i patrimoni, Girona, Brau i Universitat de Girona.

Clara, J. (1991) «Els jurats de Girona oferiren a Antic Roca la direcció de l'Estudi General (1569)», Arxiu de Textos Catalans Antics, 10, pp. 339-341.

Garriga, J. (2011) «L'edifici de les Àligues. Estudi general i funcionalisme arquitectònic cinccentista», dins VV. AA. Universitat de Girona: Història, arquitectura i patrimoni, Girona, Brau i Universitat de Girona, pp. 225-244.

Girbal, E. C. (1894) «La Universidad Literaria (datos y documentos inéditos)», Revista de Gerona, 18, pp. 115-127, 142-145 i 210-217.

Marquès, S. (2002) «L'Estudi General de Girona», dins Busqueta, J. J. i Pemán, J. (coords.), Les universitats de la Corona d'Aragó, abir i avui. Estudis històrics, Barcelona, Pòrtic, pp. 125-146.

Masià de Ros, À. (1943) Gerona en la guerra civil en tiempo de Juan II, Barcelona, C.S.I.C.

Perarnau, J. (1984) «Les primeres gestions per a l'erecció d'estudi universitari a Barcelona (1310) i a Girona (1446)», Arxiu de Textos Catalans Antics, 3, pp. 243-250.

Rossich, A. (1982) «Dades inèdites sobre l'Estudi General de Girona», Annals de l'Institut d'Estudis Gironins, XXVI, pp. 543-558.

Sobrequés, J. (1978) Els estudis universitaris a Girona al llarg de la bistòria, Girona, Col legi Universitari de Girona.

- (1975) «Població i societat a la Girona de la Baixa Edat Mitjana», dins Sobrequés, S. Societat i estructura politica de la Girona medieval, Barcelona, Curial, pp. 11-74.

Torres, X. (2001) «La ciutat de Girona a l'època moderna: de capital del drap a plaça forta», Annals de l'Institut d'Estudis Gironins, XLII, pp. 25-44.

—. (2011) «L'Estudi General de Girona (1446-1717)», dins AA. DD. Universitat de Girona: Història, arquitectura i patrimoni, Girona, Bran i Universitat de Girona, pp. 17-25.

Torroella, J. B. (1906) El Estudi General o Universitat Literària de Girona, Girona, Llibreria de P. Torres, 2a. ed. 